DOI 10.20396/temáticas.v27i53.11610

\title{
A CRISE DA FRENTE POLÍTICA NEODESENVOLVIMENTISTA E A DISCUSSÃO SOBRE O SINDICALISMO NO BRASIL
}

\author{
Francisco Prandi Mendes de Carvalho ${ }^{1}$
}

RESUMO: O presente artigo visa indicar e discutir algumas hipóteses para investigação a respeito do papel do sindicalismo durante a crise política brasileira dos anos de 2015 e 2017. Nossa argumentação está estruturada da seguinte forma: em um primeiro momento, reconstruiremos brevemente algumas características dos governos Lula e Dilma (2003 - 2016) que permitiram uma recuperação da atividade grevista em relação ao período neoliberal, que compreende os governos Collor, Itamar Franco e Fernando Henrique Cardoso (1990 - 2002). Em um segundo momento, trataremos da crise política e econômica do governo Dilma Rousseff e das disputas inauguradas a partir do momento de sua destituição, quando o sindicalismo se viu em confronto aberto com as propostas de reformas trabalhista e da previdência. Nossa hipótese principal, da qual decorrem outras secundárias, é que se o impeachment causou certa divisão entre as centrais, nessa conjuntura de restauração neoliberal as centrais sindicais encontram maiores pontos de unidade, não necessariamente em torno de táticas e estratégias, mas em torno de bandeiras de luta.

PALAVRAS-CHAVE: Sindicalismo; Crise Política; Brasil; Governos Lula e Dilma.

\section{THE CRISIS OF THE NEODEVELOPMENTALIST POLITICAL FRONT AND THE DISCUSSION ABOUT TRADE UNIONISM IN BRAZIL}

\footnotetext{
${ }^{1}$ Mestrando no Departamento de Sociologia na Faculdade de Letras, Filosofia e Ciências Humanas da Universidade de São Paulo. O presente trabalho foi realizado com apoio do Conselho Nacional de Desenvolvimento Científico e Tecnológico - Brasil. Contato: francisco. prandi.carvalho@usp.br.
} 


\begin{abstract}
This article aims to indicate and discuss a few hypotheses for investigating the role of trade unionism in the Brazilian political crisis, more precisely between the years of 2015 and 2017. My argumentation is structured in the following way: in a first moment, I briefly review some of the features of the Lula and Rousseff administrations (2003 2016) that enabled the recovery of strike action vis-à-vis the neoliberal period, which comprised the Collor, Itamar Franco, and Fernando Henrique Cardoso (1990 - 2002) administrations. In a second moment, I will address the political and economic crisis of the Dilma Rousseff administrations and the disputes triggered by her ousting, when labor found itself openly confronted with the labor and pension reforms. My main hypothesis, from which others, secondary ones, are derived, is that if the impeachment, to some extent, caused a division between the national trade union centers, at this juncture of neoliberal restoration the trade union centers share more points of unity, not necessarily around tactics and strategies, but rather around the same banners of struggle.
\end{abstract}

KEYWORDS: Trade Unionism; Political Crisis; Brazil; Lula's and Dilma's Government.

Em toda minha vida de movimento sindical, sempre achei que a questão da luta de classes era colocada no discurso político pelos de baixo. Depois das passeatas de 2013, ela foi colocada pelos de cima.

(Lula da Silva, 2018, p. 107).

\title{
CRISE DO NEOLIBERALISMO E FRENTE NEODESENVOL- VIMENTISTA
}

O neoliberalismo chega ao governo no Brasil nas eleições de 1989 com a vitória de Fernando Collor contra Lula, este último representante do campo democrático-popular (ARAÚJO \&AMP; OLIVEIRA, 2011)². A política neoliberal também predominou nos governos Itamar Franco (1992 1994) e Fernando Henrique Cardoso [FHC] (1995 - 2002). A política

\footnotetext{
${ }^{2}$ Julgamos a caracterização particularmente precisa haja vista que esse elaborou uma estratégia e um programa político denominado democrático-popular (MACHADO, mimeo). Além do PT, a CUT e o Movimento dos Sem-Terra (MST) são importantes representantes desse campo. Como afirmam Araújo e Oliveira (2011) esse campo se constitui no enfrentamento à ditadura quando essa estava em processo de derrota e o país entrava na era da redemocratização, nos anos 1980. Podemos dizer que com a chegada do PT ao governo esse campo se complexifica e se ramifica, eventualmente dando origem a novos movimentos e partidos, como o Partido Socialismo e Liberdade (PSOL).
}

Temáticas, Campinas, 27, (53): 251-284, fev./jun. 2019 
de privatizações e a reestruturação produtiva reduziram objetivamente a base social do sindicalismo, uma vez que produziram uma alta taxa de desemprego, chegando a $13,5 \%$ no final do segundo mandato de FHC (BOITO JR., et al., 2017). Nesse período, houve um grande refluxo do sindicalismo em relação aos anos 1980, quando a situação econômica com altas taxas de inflação e o processo de redemocratização do país ajudaram a constituir um ambiente favorável à ação grevista, com forte destaque para a corrente do Novo Sindicalismo no ABC, cujo líder era Luís Inácio Lula da Silva. Nos anos 1990, portanto, predominam greves defensivas (pela manutenção de direitos e empregos).

Contudo, a política neoliberal sofreu um desgaste e entrou em crise entre o final da década de 1990 e começo da década de 2000 em toda a América Latina (KATZ, 2016). As sucessivas vitórias eleitorais de candidatos críticos ao neoliberalismo, como Chávez na Venezuela (1998), Lula no Brasil (2002), Evo Morales e Rafael Correa, respectivamente na Bolívia e Equador (2006) deram uma nova feição à política latinoamericana. Como esse processo se deu no Brasil? Diferentemente da proposta que havia encampado nas eleições de 1989, o chamado campo democrático-popular em seu processo de afirmação e viabilização eleitoral por meio do PT, constituiu uma frente política com a grande burguesia interna, que se desenhou durante os anos 1990 por iniciativa do próprio movimento

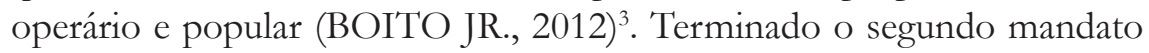
de FHC, o saldo da política neoliberal foi de grande desindustrialização, privatização, desnacionalização da economia e desemprego. De acordo com dados do IBGE, a participação da indústria cai da casa dos $45 \%$ no ano de 1985 para 25\% em 1999, a pior da série histórica do período que denominamos como neoliberal (CNI, 2016). Para os trabalhadores, havia a necessidade de emprego e, para a burguesia interna, tratava-se de manter o fundamento de sua atividade econômica. Essa aliança não se deu

\footnotetext{
${ }^{3}$ Boito Jr. (2012) ressalta que no ano de 1996 CUT, Força Sindical e Confederação Geral dos Trabalhadores fizeram uma greve contra a desindustrialização e os juros altos que contou com o apoio ativo e organizativo da Federação de Indústrias do Estado de São Paulo (FIESP), descontentes com os efeitos da política neoliberal de FHC, mas não necessariamente com o conjunto do programa neoliberal (flexibilização de direitos, terceirização, por exemplo).
} 
sem um processo de moderação política e até mesmo adoção de pontos do programa neoliberal pelo PT (MARTUSCELLI, 2015). Forma-se uma frente política que, embora por seu caráter poli classista fosse instável e contraditória, governaria durante o período relativamente longo de 13 anos $(2003$ - 2016).

Para compreender melhor esse cenário, é preciso se levar em conta que as classes sociais não constituem um bloco monolítico que se opõem de maneira simples (dominante/dominada). Em Marx é possível distinguir dois registros quando se trata de luta de classes. Em um nível maior de abstração, que o autor utiliza em obras como o Manifesto Comunista ou O Capital, há uma ênfase naquilo que seriam as chamadas "classes fundamentais", ou seja, burguesia e proletariado. Nesses textos clássicos, o problema é colocado como oposição antagônica e inconciliável. Contudo, em obras em que Marx analisa formações sociais concretas, as chamadas “obras históricas" como O 18 Brumário de Luís Bonaparte ou ainda As lutas de classes na França (1848-1850), há certa relativização desse esquema. Embora as chamadas classes fundamentais concentrem o conflito, nessas obras aparecem mais classes em luta, bem como as chamadas frações e camadas de classe (BOITO JR., 2011).

A ideia de que há frações em uma mesma classe, comporta a tese de que há a possibilidade de que haja contradições internas entre elas que podem ou não emergir enquanto força social no processo político, isto é, capazes de produzir efeitos pertinentes na conjuntura (POULANTZAS, 1977). No caso brasileiro, é possível distinguir duas frações da burguesia brasileira: a burguesia compradora, integrada ao capital estrangeiro, e a burguesia interna (BOITO JR., 2012). A ideia de burguesia interna, em Poulantzas $(1975,1978)$ consiste em uma fração da burguesia característica dos países de capitalismo dependente. Ela difere tanto das burguesias nacionais (que na visão dos antigos Partidos Comunistas poderia assumir posições anti-imperialistas nos países dependentes) quanto das burguesias perfeitamente integradas ao capital internacional, ocupando uma posição intermediária. Essa contradição auxilia na compreensão da natureza do conflito na cena política ${ }^{4}$ entre neoliberais e neodesenvolvimentistas.

${ }^{4}$ Entendemos, com Boito Jr. (2007, p. 139) que "Marx concebe a cena politica nas sociedades Temáticas, Campinas, 27, (53): 251-284, fev./jun. 2019 
O caráter neodesenvolvimentista desse período ficaria mais evidente a partir do segundo mandato de Lula, após um primeiro mandato mais próximo do capital financeiro (ALVES, 2014; KATZ, 2016; BOITO JR., 2012). Bresser-Pereira (2016a, p. 30) entende que é a partir de 2006 que o governo implementa um "social-desenvolvimentismo", , reconhecendo que foi um período marcado pela influência das ideias neodesenvolvimentistas. A esse respeito, é sintomático, como afirma Boito (2012, p. 84) o apoio ativo oferecido pela FIESP durante essa crise política que abalou o final do primeiro mandato de Lula. Contudo, autores como Braga (2012) e Singer (2012) possuem uma visão distinta da natureza do que chamam de lulismo. Para Singer (2012) essa configuração política consiste na arbitragem de conflitos, atendendo a demandas ora dos trabalhadores, ora da burguesia. Ao fazê-lo, aplicaria o programa do subproletariado ${ }^{6}$. Braga (2012) afirma que essa política combina o consentimento ativo das direções e passivo das massas, sem grandes diferenças com os governos neoliberais, consistindo em um governo da burguesia.

Entendemos, porém, que a abordagem que utilizamos possui a vantagem de demonstrar que: 1) a política dos governos de Lula e Dilma, com diferenças entre os mandatos, privilegion o interesse de uma determinada fração da burguesia e desprestigiou, em certa medida, outra fração - o que permite entender o empenho dela na deposição de Dilma ${ }^{7}$;) é preciso relativizar a ideia de uma adesão passiva a esse projeto político por parte

capitalistas" como "espaço de luta entre partidos e organizações políticas", mais precisamente uma superestrutura da luta de classes e frações de classe. Contudo, trata-se de uma "realidade superficial, enganosa que deve ser desmistificada" pela ciência social.

${ }^{5}$ Embora tenha havido uma tímida retomada da indústria no período Lula e Dilma, esse índice tornaria a cair continuamente a partir de 2013. Bresser-Pereira (2016a) sustenta que o governo Lula teria um caráter muito mais social (distribuição de renda e expansão do consumo de massas) do que desenvolvimentista (industrializante).

${ }^{6} \mathrm{O}$ subproletariado seria a maior fração da classe trabalhadora. Por sua condição precária, que remonta à herança da escravidão no Brasil, estaria abaixo das condições da luta de classes (SINGER, 2012, pp. 20-21).

${ }^{7}$ Cf. Infomoney. Depois da euforia do mercado, o ceticismo: afinal, o impeachment de Dilma esfriou?, 1/4/2016. Disponível em: <http://www.infomoney.com.br/mercados/politica/noti$\mathrm{cia} / 4821561 /$ depois-euforia-mercado-ceticismo-afinal-impeachment-dilma-esfriou $>$. Acesso em: 01/06/2018. 
das classes trabalhadoras; na nossa avaliação, ela não se sustenta tendo em vista o apoio eleitoral aos candidatos do PT - o que lança luzes sobre a discussão a respeito da atuação das centrais sindicais no período abordado. Embora hegemonizado pela burguesia interna, outras classes sociais tiveram seus interesses atendidos. Podemos citar os ganhos salariais do período para os trabalhadores formais, os benefícios advindos de políticas públicas. Os trabalhadores da massa marginal ${ }^{8}$ foram contemplados com programas como o Minha Casa, Minha Vida, o Bolsa Família, Mais Médicos, a classe média, com o aumento de concursos públicos (BOITO JR., 2012; CAVALCANTE, 2015). No campo, os programas de compra de alimentos por prefeituras e o crédito rural beneficiaram em especial os pequenos agricultores, bem como o "Luz para Todos". Em relação aos trabalhadores formais, podemos citar o programa de valorização do salário mínimo, auxílio de prestação continuada, entre outros?

Em sua relação com as classes dominadas, o Estado capitalista necessita de uma base social sobre a qual se apoiar fora do bloco no poder, o que Poulantzas (1977a) denomina classes-apoio. Diz o autor: "seu apoio a uma dominação de classe determinada não é em geral baseado em qualquer sacrificio político real dos interesses no bloco no poder e das classes aliadas em seu favor" (POULANTZAS, 1977a, p. 238 - grifos do autor). Assim, um apoio ativo da classe trabalhadora a uma determinada forma de dominação burguesa não está descartado a priori, sobretudo quando há políticas que atendem seus interesses, ainda que pontualmente e não ferem o essencial para as classes dominantes.

Entendemos com Boito Jr. (2012), Bresser-Pereira (2016a, 2016b, 2010) e Katz (2016) que o neodesenvolvimentismo é uma corrente teórico-

\footnotetext{
${ }^{8}$ Entendemos o conceito de massa marginal tal como formulado por Kowarick (1977), isto é, como parte constitutiva do capitalismo dependente na América Latina, a partir da inserção no processo produtivo. Portanto, as diversas formas de trabalho autônomo (setor terciário, ambulantes, serviços, vigilância, limpeza, trabalho doméstico remunerado etc.) entram nessa categoria. Trata-se de um fracionamento interno da classe trabalhadora que contribui para a expansão do capital na medida em que rebaixa o custo da reprodução da força de trabalho, oferecendo bens e serviços a baixos preços.

${ }^{9}$ Para mais detalhes cf. Bastos (2017, p. 80), Paulani (2017, pp. 94-95), Boito Jr. (2012), Singer (2012).
} 
política, de repercussão internacional e que ganhou força na América Latina nos primeiros anos da década de 2000 - sobretudo após a crise de $2008^{10}$. Consiste em uma estratégia nacional de desenvolvimento para países de renda média - como o Brasil, no qual o Estado deve possuir um papel indutor, inspirando-se nos países do leste asiático que se industrializaram rapidamente. Assim como o "velho" desenvolvimentismo, esse modelo também prima pela (re)industrialização ${ }^{11}$. De um lado, o Estado deve criar condições para que empresários assumam o risco de investir e inovar; em contrapartida, deve manter o superávit primário, altas taxas de câmbio, baixas taxas de juro, além de primar pela expansão do consumo, mas com controle da inflação (BRESSER-PEREIRA, 2010). Como ressalta Katz (2016), não se trata de uma oposição entre mais ou menos Estado, pois tanto os neoliberais quanto os neodesenvolvimentistas recorrem fortemente ao setor público: “o que está sempre em jogo é o tipo de intervenção estatal predominante" (KATZ, 2016, p. 164). A partir de Poulantzas (1977) entendemos que isso reflete a disputa entre as frações de classes burguesas pela hegemonia no comando do Estado capitalista.

Entretanto, o neodesenvolvimentismo é mais modesto em seus objetivos do que o desenvolvimentismo - vivido no Brasil entre as décadas de 1950 e 1980. Esse modelo não se propõe a enfrentar determinados aspectos do neoliberalismo, o que o limita fortemente. Além de concentrarse no processamento de produtos agrícolas, pecuários e de recursos

${ }^{10} \mathrm{O}$ campo neodesenvolvimentista é bastante amplo e possui muitas variantes internas. No Brasil, podemos identificar como exemplos alguns economistas como Bresser-Pereira, Pedro Zahluth Bastos (Unicamp), Nelson Marconi (Presidente do Centro de Estudos do Novo Desenvolvimentismo da Fundação Getúlio Vargas), integrado também por José Luis Oreiro. No mundo político, os ex-ministros Aloizio Mercadante e Guido Mantega, além do expresidente do IPEA João Sicsú também se identificam com essas propostas.

${ }^{11} \mathrm{O}$ conceito de doença holandesa é particularmente importante nesse ponto. Bresser-Pereira (2016a, pp. 225-228) entende que a desindustrialização do Brasil decorre fundamentalmente da abundância de recursos naturais e commodities. Disto decorre uma sobreapreciação da moeda nacional que destrói o parque industrial, na medida em que a empresa local passa a receber menos moeda local por dólar exportado. Recebendo menos, seus custos aumentam e ela deixa de exportar. A consequência, do ponto de vista do mercado mundial, é que os importadores de matéria-prima recorrem a outros mercados, tornando inevitável o processo de desindustrialização. 
naturais - que possuem baixa densidade tecnológica - ele também se volta para o mercado externo. Ao mesmo tempo, a dívida pública e os juros altos limitam as taxas de crescimento, que são bem menores que as do "antigo" modelo (BOITO JR., 2012). A visão neodesenvolvimentista também defende que a agro exportação deve fornecer divisas para financiar a reindustrialização tem como consequência uma coalizão com o agronegócio, ao contrário do conflito com a oligarquia agrária, característico do "velho" desenvolvimentismo (KATZ, 2016).

Sampaio Jr. (2012) afirma que esse "rebaixamento" em relação ao desenvolvimentismo antigo nega os fundamentos da própria ideia de desenvolvimento, não merecendo, portanto, essa qualificação. Contudo, pensamos que, feitas as devidas ressalvas, esse conceito é adequado para explicar a conjuntura brasileira a partir da década de 2000. Ele nos auxilia a compreender as diferenças dos blocos políticos (neoliberal e neodesenvolvimentista) que dominaram a cena política no período, como vimos anteriormente. $\mathrm{O}$ êxito ou não dos objetivos que uma determinada corrente se propõe não anulam sua existência teórico-política. Além disso, as mudanças nos níveis de desenvolvimento, as políticas econômicas e sociais mais distributivas desse período (2003-2015) parecem autorizar a diferenciação. Embora características estruturais de degradação do trabalho persistissem (ampliação da terceirização, alta taxa de rotatividade do trabalho, precarização, entre outras), os indicadores do mercado de trabalho se mostraram bastante positivos, mesmo após a crise de 2008 e até 2013 (índice de formalização, crescimento da massa de rendimentos médios reais, aumento real de salário mínimo ${ }^{12}-77 \%$ de valorização real entre 2003 e 2015) (ALVES, 2014; Ladosky \&amp; Rodrigues, 2018, p. 57). Essa é uma diferença importante com o período neoliberal, cuja dinâmica do mercado de trabalho era inversa, o que auxilia a compreender melhor a relação entre os governos neodesenvolvimentistas e as centrais sindicais.

\footnotetext{
${ }^{12}$ Paulani (2017) destaca que essa foi a maior política de combate à desigualdade no período.
} 


\section{A RECUPERAÇÃO DO SINDICALISMO: UM CICLO DE GREVES OFENSIVO (2003 - 2013)}

A chegada de Lula ao governo colocou novos desafios para o movimento sindical, em especial para a CUT e os movimentos sociais que apoiaram a candidatura do presidente eleito. Um exemplo desses desafios é como apoiar um governo que havia ajudado a eleger e, ao mesmo tempo manter a autonomia reivindicativa. As condições de atuação do sindicalismo haviam mudado. Braga (2012, pp. 204-206) ressalta que, durante o primeiro mandato de Lula da Silva, sindicalistas compunham metade dos cargos superiores de direção e assessoramento do governo Federal, controlando um orçamento anual superior a 200 bilhões de reais. Além disso, presidências de estatais e postos-chave também foram ocupados por sindicalistas: fundos de pensão, a Petrobras, Furnas, o Banco Nacional de Desenvolvimento Econômico e Social, bem como o Conselho de Desenvolvimento Econômico e Social (CDES). Além disso, como destaca Cardoso (2015, p. 503) Antônio Palocci, Luís Marinho, Luis Gushiken, Jaques Wagner, para citarmos alguns exemplos, eram ministros importantes cuja trajetória política estava vinculada ao movimento sindical. Houve diversos mecanismos de participação institucional que envolveram o sindicalismo, sobretudo durante os mandatos de Lula, como no caso do Fórum Nacional do Trabalho, que envolveu empresários, representantes governistas e sindicais para discutir as legislações trabalhista e sindical e buscar consensos (Ladosky \&amp, Rodrigues, 2018).

Neste período, com algumas exceções, a maioria das centrais sindicais apoiou este governo, mais especificamente: a Central Única dos Trabalhadores (CUT), a Central dos Trabalhadores e Trabalhadoras do Brasil (CTB), a União Geral dos Trabalhadores (UGT), a Nova Central Sindical dos Trabalhadores (NCST) e a Força Sindical - que em 2014 apoiaria uma candidatura de oposição. Além de ter sido uma força política reconhecida como aliada pelo governo e frequentemente consultada em relação às políticas públicas, o sindicalismo recuperou a atividade grevista, que esteve em declínio nos anos 1990 (BOITO JR.\&amp; MARCELINO, 2010). O levantamento empírico do número de greves no país, realizado 
pelo DIEESE (Departamento Intersindical de Estatística e Estudos Socioeconômicos), demonstra um aumento significativo e contínuo dessa modalidade de ação sindical, além de uma importante vitalidade da base. No ano de 2004, quando se inicia uma retomada do crescimento econômico no Brasil, são registradas 302 greves; em 2013 esse número salta para o recorde de 2.050 greves, com ganhos reais para os trabalhadores em acordos coletivos e salários em todo esse período (BRAGA, 2016; BOITO JR. et al, 2015; CARDOSO, 2014; BOITO JR.\&amp; MARCELINO, 2010).

Podemos afirmar, desse modo, que esses elementos indicam vitalidade do movimento sindical no Brasil, desde que se faça a ressalva de que essa vitalidade não extrapola determinados traços históricos estruturais do sindicalismo brasileiro. Como demonstra Cardoso (2015), entre 2002 e 2013 as taxas de filiação oscilaram, mantendo-se baixas e em tendência de queda. Entendemos, que isso decorre de uma estrutura sindical cuja sobrevivência não está ligada à necessidade de filiação e autossustentação (BOITO JR., 1991). Do ponto de vista das cúpulas, um aspecto importante é o surgimento de novas centrais sindicais ${ }^{13}$ entre 2003 e 2016, o que indica que há uma disputa na cúpula pela base de trabalhadores (GALVÃO, 2012). A noção de disputa pela base comporta a ideia de que há, também, uma disputa sobre as concepções de sindicalismo não apenas entre as centrais como também em casos de disputa interna no âmbito das centrais.

Por exemplo, nas centrais sindicais que se reivindicam de esquerda aparece de modo mais claro uma visão positiva sobre a necessidade do partido político. Há um histórico debate sobre o tema que remonta ao início do século $\mathrm{XX}$, no qual se envolveram dirigentes marxistas como Lenin, Gramsci, Trotsky e Rosa Luxemburgo. No Brasil, poderíamos

\footnotetext{
${ }^{13}$ Além da CUT e da Força Sindical, que já disputavam a base nos anos 1990, surgem, a partir de 2004 as seguintes centrais: Conlutas, Intersindical - Central da Classe Trabalhadora, União Geral dos Trabalhadores (UGT), Central dos Trabalhadores e Trabalhadoras do Brasil (CTB), Central dos Sindicatos Brasileiros (CSB), NCST (Nova Central Sindical dos Trabalhadores), Central Brasileira Democrática dos Trabalhadores (CBDT), Pública, Central Unificada dos Servidores Públicos do Brasil e União Sindical dos Trabalhadores (UST) (MINISTÉRIO DO TRABALHO, 2016).
} 
citar a vinculação histórica que as centrais de esquerda possuem com partidos políticos: a CUT, hegemonizada por forças ligadas ao Partido dos Trabalhadores (PT); a CTB, oriunda da Corrente Sindical Classista - que atuava até 2007, ano de fundação da central, na CUT, vinculada ao PCdoB; a Intersindical, hegemonizada por forças vinculadas ao PSOL; a Conlutas composta de forças ligadas ao PSTU, em primeiro lugar, e ao PSOL (GALVÃO, 2012). Em contrapartida, UGT, Força Sindical, NCST e CSB não têm uma hegemonia partidária tão marcada quanto as anteriores, embora eventualmente suas lideranças sindicais estejam vinculadas a partidos políticos no lado direito do espectro político nacional.

Desde os primeiros momentos do governo Lula da Silva se estabeleceu no seio das Ciências Sociais no Brasil um intenso debate sobre o papel do sindicalismo no processo político. Podemos dizer que esses estudos são unidos por uma preocupação comum, a saber, compreender qual o lugar ocupado pelo sindicalismo enquanto força política nos governos Lula da Silva e Dilma. Essa discussão permeia uma série de outros aspectos como, por exemplo, o caráter das direções sindicais, isto é, se representariam ou não os interesses das classes trabalhadoras, se os dirigentes sindicais estão na condução do Estado ou não, ou ainda, se esses governos atenderam ou não os interesses de classe dos trabalhadores. Em 2003, primeiro ano do governo Lula, houve uma reforma da previdência que retirou direitos do funcionalismo público e frustrou a base social de apoio ao governo, avaliação comum tanto de sindicalistas da CUT quanto da Conlutas (FERRAZ \&amp; BRIDI, 2014). Apesar desse desgaste inicial, no ano de 2004 o governo optou por realizar o Fórum Nacional do Trabalho, que reuniu membros do governo, do empresariado e sindicalistas para discutir as reformas sindical e trabalhista. As propostas acabaram não sendo implementadas e o único saldo foi a Lei de Reconhecimento das Centrais Sindicais, sancionada por Lula em 2008 (GALVÃO, 2012).

Hoje, na literatura, é possível distinguir três grupos de teses sobre a relação entre o sindicalismo e os governos Lula e Dilma (2003 - 2016): 1) o sindicalismo chegou ao governo por meio de uma elite dirigente, vinculada sobretudo à CUT (CARDOSO, 2014, 2015; SÓRIA E SILVA, 2011; OLIVEIRA, 2003); 2) o sindicalismo foi cooptado pelo governo, 
perdendo a capacidade combativa que teve no passado e se subordinando a ele (DRUCK, 2006; MATTOS, 2009; ANTUNES, 2011; BRAGA, 2012; SOARES, 2013); 3) a) tanto a ideia de que o sindicalismo foi cooptado, quanto a de que ele foi governo precisam ser relativizadas, em que pese seu apoio a esses governos; b) houve uma reconfiguração no cenário sindical como surgimento de novas centrais (BOITO JR \&amp; MARCELINO, 2010; GALVÃO, 2012; LADOSKY et al., 2014; MARCELINO et al., 2015; BOITO JR. et al., 2015; MARCELINO, 2017).

Autores como Oliveira (2003), Sória e Silva (2011), Cardoso (2014) identificam uma mudança na elite governante no Brasil. Os sindicalistas teriam chegado ao poder no governo Lula. Oliveira (2003) afirma que se trata de uma nova classe social no poder, cujas origens remontam às "capas mais altas do proletariado", mas teria uma especificidade na gestão dos fundos de pensão públicos, não podendo ser caracterizada como burguesia. Essa "nova classe" seria a responsável por mudanças programáticas do PT em relação ao passado. Embora essa tese tenha sido criticada, ela inaugurou a discussão e influenciou autores como Sória e Silva (2011) e Braga (2012). Sória e Silva (2011) entende que os fundos de pensão não seriam o suficiente para gestar uma nova classe social. Mas produziram aquilo que denomina como intersecção de classe, isto é, um ponto no qual capital e trabalho se tocam, mas não se fundem. Esses sindicalistas e ex-sindicalistas embora sejam gestores dos fundos de pensão não são proprietários dos recursos que administram.

Cardoso (2014), por sua vez, compreende que o governo Lula seria a expressão mesma do projeto tanto da CUT quanto da C'TB, não cabendo a ideia de cooptação. Em sua análise, a CUT chega ao poder com Lula, o que também faz nascer uma elite de "extração popular, com lastro no mundo do trabalho, aptas à gestão do Estado capitalista" (CARDOSO, 2014, p. 140). Ainda de acordo com Cardoso (2015, p. 503), o governo Lula teria cumprido a profecia varguista de que os trabalhadores "um dia seriam governo, e dariam à acumulação capitalista condições socialmente menos turbulentas para prosperar". Contudo, o aumento da influência e da participação do sindicalismo na política não significa que ele tenha a direção desse processo mais amplo, sobretudo porque "parte minoritária 
das proposições do sindicalismo é efetivamente discutida nos espaços institucionais assegurados pelo governo e uma parte menor ainda é posta em prática" (BOITO JR. et al, 2015, p. 214). Desse modo, julgamos impreciso caracterizar os governos encabeçados pelo PT como "dos sindicalistas". Algumas reivindicações históricas, como a redução da jornada de trabalho para 40 horas semanais sem redução salarial sequer foram postas em discussão nesses 13 anos de governo. Embora a composição social do governo contasse com esses quadros, os governos neodesenvolvimentistas expressaram mormente os anseios da grande burguesia interna, como já vimos, sendo esse o caráter de classe de tais governos.

Há também um grupo de autores (BRAGA, 2016, 2012; ANTUNES, 2011; SOARES, 2013; MATTOS, 2009; DRUCK, 2006) que entende que o sindicalismo teria passado por um processo de cooptação durante o governo Lula. Como podemos ver em entrevistas feitas por Ferraz e Bridi a dirigentes sindicais (2014), essa tese não se restringe ao meio acadêmico. A CSP-Conlutas e a Intersindical, centrais saídas da CUT que foram oposição aos governos de coalizão encabeçados pelo PT, defendem essa tese. Esse grupo de autores referidos acima não fala na constituição de uma elite, mas de uma burocracia sindical ${ }^{14}$ que teria liderado um processo de moderação política e se acomodado com o governo. $\mathrm{O}$ ascenso grevista é explicado por esse grupo como parte de uma reação das bases ao imobilismo das direções, mais explicitamente no caso de Soares (2013) e Braga (2016, 2012).

Um problema das análises anteriormente referidas é que, com exceção de Soares (2013), todas tratam apenas do sindicalismo cutista. Elementos como a fundação de mais centrais sindicais e rearranjo de forças do sindicalismo passam despercebidos por essa bibliografia. Há, nesses autores, uma ideia geral de que na medida em que a burguesia e o

\footnotetext{
${ }^{14} \mathrm{O}$ conceito burocracia, no seio do marxismo, corrente à qual os autores de que trataremos nessa seção se filiam (ANTUNES, 2011; BRAGA, 2012; DRUCK, 2006; SOARES, 2013), encontra sua base principal nas análises de Trotsky. De maneira bastante sintética, a ideia geral que se deve ter presente quando se trata de burocracia sindical é a de uma direção que se apropria do aparelho sindical sem poder oferecer uma perspectiva revolucionária ao proletariado. Para Trotsky (2008, p.197), essa burocracia, que se opõe "a todo passo audaz das massas" é composta por funcionários "rotineiros e carreiristas".
}

Temáticas, Campinas, 27, (53): 251-284, fev./jun. 2019 
governo ofereciam ganhos imediatos à classe trabalhadora e os dirigentes sindicais gozavam de benesses do aparelho de Estado, os sindicatos teriam se acomodado. Contudo, como vimos anteriormente há elementos materiais que permitem sustentar a tese de que houve uma adesão por parte da maioria da classe trabalhadora a esse governo, apoio expresso fundamentalmente nas eleições e na não realização de greves gerais contra a política econômica dos governos nesse período (MARCELINO, 2017 pp. 218-219).

Assim, entendemos com aquele terceiro grupo de autores (MARCELINO, 2017; GALVÃO, et al, 2015; BOITO JR. et al, 2015; LADOSKY et al, 2014; GALVÃO, 2012; BOITO JR \&amp.; MARCELINO, 2010) não se pode subestimar a ideia de que houve uma adesão consciente por parte da classe trabalhadora a esse projeto encabeçado pelo PT; menos ainda quando se trata de subestimar a ação das bases diante da cúpula, pois, como argumentam Galvão et al. (2015) se o descolamento entre base e direção fosse completo não seria possível explicar a filiação sindical a uma determinada central. Assim, as posições da cúpula em alguma medida devem representar os anseios da base sindical. Desse modo, esse grupo de autores trata de relativizar tanto a ideia de que o sindicalismo foi governo, quanto a de que ele foi cooptado pelos governos Lula e Dilma.

Embora esse grupo seja o mais heterogêneo, há importantes pontos de convergência. A tese mais presente é a de que o sindicalismo integrou, como força subalterna, uma frente política neodesenvolvimentista encabeçada pelo PT que levou a cabo uma política que, embora privilegiasse os interesses de uma determinada fração da burguesia, atendeu também interesses de classe dos trabalhadores. Também há de se destacar um esforço, sobretudo nos trabalhos de Galvão (2012) e Galvão et al. (2015) em compreender as novas centrais sindicais surgidas nesse período, enfatizando as relações entre bases sociais e comportamento político de cada central.

Galvão (2012) argumenta que o surgimento de novas centrais sindicais (à esquerda e à direita) indica uma reconfiguração no cenário sindical que comprometeu a hegemonia que CUT e Força Sindical tiveram na disputa 
da base nos anos 1990 e começo da década de 2000. Mas isso também tem relação com escolhas políticas que descontentaram a base sindical. De um lado, a Força sindical, que deu um excessivo apoio ao neoliberalismo; de outro a CUT e seu excessivo apoio aos governos petistas, mesmo em momentos em que ele contrariou interesses dos trabalhadores. Ladosky et al. (2014), em contrapartida, afirmam que embora a proximidade com o governo tenha dificultado que a CUT assumisse posturas mais críticas em determinados momentos, isso não quer dizer que esta central tenha sido tomada por uma paralisia. Desse modo, os autores também dizem que a CUT pode não ter tido a visibilidade que teve nas grandes mobilizações dos anos 1980, mas que a interlocução com o governo aumentou sua eficácia política. Portanto, houve conquistas que em outras conjunturas políticas e ideológicas de distanciamento do governo não seriam possíveis.

Deste panorama, levantamos uma das nossas primeiras hipóteses, a de que, embora o sindicalismo tenha recuperado a ação grevista no período, isso não se converteu em um saldo organizativo que permitisse o enfrentamento das reformas propostas por Michel Temer (MDB - SP) no período posterior. Embora o PL 4330/04, que liberava a terceirização irrestrita para atividades fim e meio, tenha sido derrotado, após uma série de mobilizações, que contou com duas greves gerais, a reforma trabalhista foi aprovada em 2017 com relativa tranquilidade e, mais recentemente, em julho de 2019, a reforma da previdência foi aprovada em primeiro turno, em contraste com o governo Temer que não conseguiu aprovar esta última.

\section{O SINDICALISMO NA CRISE POLÍTICA E ECONÔMICA (2015 - 2017): GOLPE E RETOMADA DA AGENDA NEOLIBERAL}

Lula encerrou o mandato com $87 \%$ de aprovação $^{15}$ e Dilma, antes das manifestações de junho de 2013 teve $79 \%{ }^{16}$. Contudo, esse

\footnotetext{
${ }^{15}$ Ver Portal G1. Popularidade de Lula bate recorde e chega a 87\%, diz Ibope. 16/12/2010. Disponível em: < http://g1.globo.com/politica/noticia/2010/12/popularidade-de-lula-bate-recorde-echega-87-diz-ibope.html >. Acesso em: 22/03/2018.

${ }^{16}$ Ver UOL Notícias - Política. Dilma é aprovada por $79 \%$ e supera Lula e FHC, diz CNI/ 
período de relativa estabilidade teve seu primeiro grande desgaste com as manifestações de junho de 2013. A aprovação da presidente Dilma Rousseff despencou e não retomaria os índices do passado até sua deposição em agosto de 2016 - embora ela tenha sido reeleita em pleito de 2014. O baixo crescimento econômico em 2014, com queda de 4,4\% em relação ao ano anterior, também contribuiu para colocar o governo na defensiva, cortando os gastos públicos (SINGER, 2016). Nesse momento, as contradições que estavam latentes emergiram com força na conjuntura. À sua reeleição em disputa acirrada contra o candidato Aécio Neves (PSDB), no segundo turno ${ }^{17}$, se seguiu a coexistência de uma crise econômica e uma crise política que abalou severamente as bases sociais de seu governo, culminando no impeachment em agosto de 2016 (SINGER, 2016; BOITO JR., 2016; BRAGA, 2016). Na campanha eleitoral de 2014, a então candidata à reeleição Dilma Rousseff insistia que o rumo da política econômica não seria alterado, o que parecia ser verdadeiro pela manutenção dos índices de emprego e salário. Criticava seu adversário e denunciava sua relação com o capital financeiro internacional e seu programa de ajuste, apesar de ter realizado um grande contingenciamento de investimentos públicos em 2013 e 2014 (SINGER, 2018, p. 125). Porém, no curso do processo eleitoral, demitiu o então Ministro da Fazenda, Guido Mantega. Após sua reeleição, optou, em novembro de 2014, por substituí-lo por um nome do mercado financeiro: Joaquim Levy, ex-diretor-superintendente do Banco Bradesco (BASTOS, 2017). Essa "virada" na condução da política econômica não apenas frustrou seu eleitorado como também não foi suficiente para reconquistar o apoio da burguesia interna e do mercado financeiro. Aqui levantamos outra hipótese: uma das consequências dessa opção foi o afastamento do movimento sindical organizado da base de apoio ao governo. Desse ponto de vista, foi ilustrativa a reação contrária às

Ibope. 19/03/2013. Disponível em: < https://noticias.uol.com.br/politica/ultimas-noticias/2013/03/19/dilma-cni-ibope.htm >. Acesso em: 22/03/2018.

${ }^{17}$ Logo após o segundo turno, o PSDB endureceu o discurso e chegou a contestar o resultado das eleições, exigindo que se fizesse uma auditoria das urnas. Além disso, líderes do partido afirmaram que o sistema eleitoral brasileiro é "inauditável" e "vulnerável". Contudo, sua auditoria concluiu que não houve fraude nas eleições de 2014. Ver Valor Econômico. Auditoria do PSDB nas eleições presidenciais de 2014 não aponta fraude (04/11/2015).

Temáticas, Campinas, 27, (53): 251-284, fev./jun. 2019 
Medidas Provisórias 664 e 665 - a primeira restringia o acesso ao auxíliodoença e o recebimento da pensão em caso de morte pelo dependente, enquanto a segunda restringia o acesso ao seguro-desemprego e ao abono salarial (GALVÃO \&amp; MARCELINO, 2018). Isso contrastava fortemente com o discurso adotado no segundo turno de que "nem que a vaca tussa" a presidente mexeria nos direitos trabalhistas.

Paulani (2017) e Morais (2017) argumentam que quando eclodiu a crise de 2008, o governo conseguiu driblar seu impacto no país por meio de uma agressiva expansão do crédito e investimentos públicos em infraestrutura. Entre 2011 e 2012, ainda no primeiro mandato de Dilma Rousseff, a opção em termos de política econômica tinha sido outra: redução de juros e forçar os spreads $^{18}$ para baixo fez com que o mercado financeiro entrasse abertamente em conflito com o governo, o que não havia ocorrido no período de Lula (SINGER, 2016). Contudo, a ideia de que a crise havia sido superada se mostrou equivocada e seus efeitos se fizeram sentir já no início do primeiro mandato de Dilma Rousseff, em 2011. A queda do preço das commodities e a redução da sua demanda pela China impactaram na economia nacional. As entidades empresariais, embora tivessem boa parte de suas reivindicações atendidas pelo governo, passaram a criticar o intervencionismo estatal e o que chamavam de ineficiência, ou seja, os gastos públicos. Por outro lado, Dilma propôs que as parcerias público-privadas tivessem margem de lucro limitada para as empresas e restringiu a possibilidade de privatizações nas concessões públicas (SINGER, 2016). Singer (2018, p. 77) destaca que embora a presidente tenha resistido, ao menos parcialmente, ao neoliberalismo em seu primeiro mandato, "o ritmo médio de expansão do PIB do segundo governo Lula, de 4,7\%, caiu para 2,4\% nos quatro anos iniciais de Dilma”.

\footnotetext{
${ }^{18}$ De acordo com o Banco Central do Brasil, entende-se por spread a diferença entre a taxa de juros de aplicação e captação. Dessa forma, ele abrange o lucro e o risco relativo às operações de crédito. Também diz respeito à diferença entre o preço de compra e de venda de título de uma determinada moeda. Ele especifica o prêmio adicional que deve ser pago por um devedor em relação em relação a uma taxa de referência. Varia, portanto, de acordo com a qualidade de crédito do emissor, o prazo, as condições de mercado, o volume e a liquidez da emissão ou empréstimo. Ver: Glossário - Banco Central do Brasil. Disponível em: http://www.bcb.gov. br/pt-br/\#!/c/GLOSSARIO. Acesso em: 28/03/2018.
} 
O agravamento da luta pelo fundo público e, a partir do final de 2012, a queda da taxa de investimento ajudaram a deteriorar a situação do governo e da economia (MORAIS, 2017; PAULANI, 2017).

Podemos afirmar que a crise política do impeachment de Dilma Rousseff mudou as condições de atuação do sindicalismo no país, exigindo uma nova postura das centrais sindicais frente ao governo, sobretudo pela agenda de reformas consideradas nocivas aos trabalhadores pelas centrais. O ciclo grevista tratado anteriormente contribuiu para a ruptura da aliança de classes que sustentou a frente política neodesenvolvimentista - seguindo as indicações de Singer (2016), Boito Jr. (2016) e Braga (2016). Desse modo, é possível que a crise política seja, dentre outros fatores e em alguma medida, a expressão desse ciclo de greves. Assim, a principal hipótese a ser investigada é a de que as centrais sindicais enfrentaram maior dificuldade em mobilizar sua base na disputa do impeachment (entre dezembro de 2015 e agosto de 2016) do que na contraposição à agenda de reformas do governo Temer.

Em seu segundo mandato, a tentativa de ajuste fiscal em um momento no qual a economia mundial se encontrava em retração fracassou. De acordo com Morais (2017), Paulani (2017) e Bastos (2017), esse momento é o menos adequado para uma política deste tipo. O resultado foi o aprofundamento da recessão e aumento do desemprego, o que solapou a base social de apoio ao governo e abriu caminho para facilitar o prosseguimento do impeachment. Singer (2016, p. 53) afirma que pluralidade de camadas prejudicadas contribuiu fortemente para o isolamento político da presidente, permitindo que a crise política desembocasse em seu impeachment, argumento também de Morais (2017), Paulani (2017) e Bastos (2017). A esse cenário de degradação econômica, somou-se uma operação deflagrada no ano de 2014 pela Polícia Federal com o objetivo de investigar casos de corrupção na Petrobrás, denominada de Lava Jato. Essa operação impactou fortemente a economia e a cena política no país. Do ponto de vista econômico, Bastos (2017) argumenta que a resistência da Operação em realizar acordos de leniência prejudicou a fração da burguesia próxima do governo (setor naval, indústria pesada e construção civil), colocando alguns de seus executivos na cadeia e inviabilizando economicamente as 
empresas e obras de infraestrutura. Ao atingir partidos, políticos e aliados do então governo, a estabilidade política também foi comprometida.

A partir de 16/10/2014, movimentos de direita passam a organizar manifestações pedindo "fora PT", "fora Dilma" e "fora corruptos" (TATAGIBA et al, 2015). Essas manifestações de rua se massificam sobretudo em São Paulo, passando a defender abertamente o impeachment no dia 16/08/2015. Nessas manifestações, a tônica era o discurso anticorrupção, com o protagonismo das classes médias (CAVALCANTE, 2015) ${ }^{19}$. Em 2015, a Força Sindical e a CGTB criaram a Frente Popular Fora Dilma com o intuito de mobilizar suas bases pela queda da então presidente, juntamente com outras forças políticas como o Partido Popular Socialista (PPS) e o partido Solidariedade, de oposição ao governo ${ }^{20}$. No ato do Primeiro de Maio organizado pela Força Sindical, além de haver um esforço por parte da Central de recolher assinaturas em defesa do impeachment de Dilma, Aécio Neves e Eduardo Cunha fizeram discursos com esse mesmo teor. Nesse mesmo ano, na convenção nacional do PSDB, o ex-candidato à presidência Aécio Neves afirmou que o PT era uma "organização criminosa" e que Dilma Rousseff não concluiria o mandato ${ }^{21}$.

$\mathrm{O}$ setor do sindicalismo historicamente vinculado à esquerda procurou responder a essa conjuntura não apenas convocando sua base

\footnotetext{
${ }^{19}$ Como demonstra Singer (2012), a classe média se afasta eleitoralmente do PT nas eleições de 2006. Para Cavalcante (2015) as razões materiais desse afastamento, como a elevação do preço dos serviços domésticos tradicionalmente consumidos pela classe média, são potencializadas pela ideologia. A hipótese de Cavalcante (2015) é a de que a ideologia meritocrática, característica dessa classe, se reflete na aversão à políticas sociais de amplo alcance. São exemplos a expansão de vagas em universidades (públicas e privadas) ou a expansão da renda das classes populares. Isso se agrava quando estas passam a frequentar lugares tradicionalmente reservados à classe média.

${ }^{20}$ Cf. Hora do Povo. Sindicalistas, movimentos sociais e partidos criam a Frente Popular Fora Dilma. Disponível em: <http://www.horadopovo.com.br/2015/04Abr/3332-01-04-2015/P3/pag3d. htm>. 01/04/2015. Acesso em: 19/09/2017.

${ }^{21}$ Ver O Globo. Em convenção, Aécio diz que Dilma não concluirá o mandato e faz apelo por unidade no PSDB, 05/07/2015. Disponível em: < https://oglobo.globo.com/brasil/em-convencao-aecio-diz-que-dilma-nao-concluira-mandato-faz-apelo-por-unidade-no-psdb-16667961 >. Acesso em: 29/03/2018.
} 
para atos de rua, mas também procurando fortalecer sua relação com os movimentos sociais. Cardoso (2015, p. 499) recorda que no dia 15 de abril de 2015 a maioria das centrais sindicais, juntamente com o MST, mobilizaram mais de 100 mil trabalhadores em todo o Brasil e realizaram diversas paralisações contra o PL 4330, projeto que liberava a terceirização irrestrita, tanto para atividades fim quanto meio das empresas. $\mathrm{O}$ autor também destaca que essa ação teve forte impacto na mídia e no Congresso.

A Frente Brasil Popular e a Frente Povo Sem Medo são novidades desse novo período. A primeira, mais próxima do governo Dilma, contava com o apoio da CUT e da CTB, vinculadas respectivamente ao PT e ao PCdoB (Partido Comunista do Brasil). A segunda, embora marcando maior distanciamento das políticas do neodesenvolvimentismo, sobretudo do segundo mandato de Dilma, também contava com a presença da CUT, da CTB e da União Nacional dos Estudantes - próximas ao governo. Contudo, é majoritariamente composta por forças que se opuseram ao governo ou que defendiam uma política de independência em relação a ele, como o Movimento dos Trabalhadores Sem-Teto, bem como a central sindical a Intersindical, próxima ao Partido Socialismo e Liberdade.

Contudo, embora as centrais tenham se posicionado, Galvão e Marcelino (2018) defendem que esse apoio, logístico e político, não mobilizou as bases, que permaneceram relativamente ausentes da disputa em torno do impeachment de Dilma. Além da já citada frustração com a guinada neoliberal de Dilma Rousseff, levantamos como hipótese de que pode ter havido uma percepção por parte dos trabalhadores de que a crise política era uma disputa entre "elites" - termo aqui utilizado de modo genérico - na qual eles não tomavam parte. Entendemos que a ideia de que a grande maioria dos trabalhadores não se sentia representada por nenhum dos lados, ou ainda a dissimulação dos conflitos de classe na cena política, cumpre um papel importante neste ponto. Além disso, não descartamos também a hipótese de que houvesse entre os trabalhadores a ideia de que o impeachment não era possível, ou não impactaria diretamente em seu cotidiano, seja pelo discurso triunfalista adotado pelo governo ${ }^{22}$,

${ }^{22}$ Um exemplo desse discurso foi a divulgação de uma lista de 186 deputados contrários ao impeachment dia 13 de abril, 4 dias antes da votação, pela deputada Luciana Santos (Partido 
seja pela tradição no Brasil de acordos pelo alto e conciliação. De igual modo, é notável o fato de que Dilma Rousseff compareceu a apenas um ato público contra o golpe: o primeiro de maio de 2016 em São Paulo. O que também indica que a mobilização de massas não era a estratégia prioritária do governo.

No dia 2 de dezembro de 2015, quando o então presidente da Câmara Eduardo Cunha (Movimento Democrático Brasileiro/MDBRJ) autorizou a abertura do processo de impeachment de Dilma Rousseff, explicitou-se que havia no Brasil uma crise política. No dia 3 de dezembro de 2015, porém, houve uma espécie de "último suspiro" da frente neodesenvolvimentista: a carta Compromisso com o desenvolvimento. Liderada pelas centrais sindicais (CUT, Força, CTB, NCST e UGT), sindicatos, federações e confederações sindicais, bem como diversas associações empresariais vinculadas à grande burguesia interna ${ }^{23}$ defenderam em Brasília a retomada do crescimento econômico, do investimento público, a utilização de mecanismos constitucionais que punissem acusados de corrupção, mas que permitissem a retomada da construção civil, dentre outras iniciativas. Também foi encaminhada a proposta de um fórum tripartite entre representantes sindicais, empresários e governo para discutir uma agenda comum. Isso demonstra que o desfecho da crise política com a deposição de Dilma e a desintegração da frente neodesenvolvimentista não estava dado desde início, isto é, houve tentativas de repactuação ${ }^{24}$.

Comunista do Brasil - PE). A lista teria sido articulada pelo ex-presidente Luís Inácio Lula da Silva e, em tese, mostrava que a deposição da presidente não ocorreria (Folha de S. Paulo, 14/04/2016). Disponível em: < https://www1.folha.uol.com.br/poder/2016/04/1760844lula-articula-frente-com-assinaturas-suficientes-para-barrar-impeachment.shtml $>$. Acesso em $12 / 02 / 2019$.

${ }^{23}$ Além da Confederação Nacional da Indústria, representantes dos fabricantes de máquinas, brinquedos, do setor automobilístico e têxtil endossaram o manifesto.

${ }^{24}$ Antes disso, em 31 de julho de 2015, Lula recebeu lideranças da Força Sindical em seu Instituto para discutir o que seria o "pós-crise". Na ocasião, o presidente da central, Miguel Torres, evidenciou que havia uma cisão: "Tem dirigente que defende o impeachment, a renúncia. A Força não trabalha com isso. Também não sei se seria melhor (se acontecesse)". O dirigente também criticou a falta de diálogo da presidente tanto com trabalhadores quanto com empresários. A reportagem do site da central destaca ainda que Paulinho da Força era um dos principais articuladores do impeachment (Força Sindical, 31/07/2015). 
Mesmo o impeachment não era consensual na oposição até pouco tempo antes da votação (SINGER, 2018, pp. 167-177). No início de 2016, houve uma grande ofensiva dos defensores do impeachment que contribuiu para a total desarticulação da frente política neodesenvolvimentista.

A admissibilidade do impeachment foi votada no dia 17 de abril de 2016. De acordo com Limongi (2017), boa parte da derrota do governo na votação parlamentar está ligada ao descontentamento na sociedade com a situação econômica, bem como a ineficácia do governo em não permitir que a Lava Jato atingisse o sistema político. Isso explicaria, ainda em sua visão, que boa parte dos votos pelo impeachment veio de partidos ainda considerados aliados ou que o eram até pouco tempo antes. Contudo, mesmo antes, Eduardo Cunha já havia ameaçado o governo com as chamadas "pautas bomba", que comprometiam o orçamento previsto anteriormente pela União. Vale ressaltar também que Cunha colocou em pauta a votação da admissibilidade do impeachment somente depois de o governo afirmar que não pressionaria seus deputados a votarem em favor do Deputado na Comissão de Ética do Parlamento. Somados ao fato de que houve uma aplicação retroativa da questão dos créditos suplementares e de que a perícia do Senado comprovou que Dilma não teve participação nos supostos crimes de que era acusada ("pedaladas fiscais") pode-se qualificar esse processo de golpe. Trata-se de um golpe de novo tipo, com novas características, distintas dos golpes militares que assolaram o continente americano nas décadas de 1960, 1970 e 1980, que certamente merece a atenção dos analistas. Contudo, um estudo como esse extrapola os limites do nosso objeto.

O que estamos entendendo por crise politica e por que insistir em sua especificidade? De acordo com Poulantzas (1977b), as crises políticas consistem em uma situação particular de condensação das contradições entre as diversas classes e frações de classe. Ela incide, portanto, em uma determinada conjuntura modificando substancialmente as relações de força, alianças de classe, o bloco no poder, podendo até fazer emergir novas forças sociais e alterar a forma de Estado ou governo em uma determinada formação social. Poulantzas (1977b) argumenta também que as crises políticas não seriam necessariamente uma anomia disfuncional 
para as classes dominantes, uma vez que podem contribuir para restaurar a hegemonia de uma fração da classe dominante ou realizar acomodações no seio do bloco no poder. A isso, Saes (1998, p. 141) denominava crises "positivas" para as classes dominantes. Portanto, nem toda crise política evolui para o que Gramsci (1978, p. 55) chamava de "crise de hegemonia", ou "crise do Estado no seu conjunto", isto é, uma crise que coloca em risco a hegemonia da classe dominante na condução do Estado. Esse entendimento é mais adequado à nossa problemática do que outros métodos de explicação ou interpretação do fenômeno das crises políticas. Dobry (2014), por exemplo, embora trate exaustivamente desse tema, afirma que em seu esquema está completamente ausente a busca pela natureza da crise política, cujas raízes, do ponto de vista marxista, devem ser buscadas no conflito distributivo de classes. Evidentemente que os fatores que permitem decifrar a natureza da crise são múltiplos e um artigo como esse não daria conta de elencá-los. Por isso, tratamos de retomá-la sempre à luz do nosso objeto condutor: as centrais sindicais.

Poulantzas (1977b) considera errôneo afirmar que as crises políticas emergem subitamente, uma vez que são processos efetivos com ritmos próprios, tempos fortes e fracos, de maior ou menor intensidade. Essa ideia também comporta a tese de que nem sempre há uma coincidência entre crise política e crise econômica, cada uma delas possui "tempos distintos" e ritmos próprios, embora possam se condicionar mutuamente. Nesse aspecto, Boito Jr. (2016) insiste que o ciclo grevista inaugurado em 2004 que permitiu ganhos salariais contínuos e crescentes, deu condições para o sindicalismo elevar suas exigências a partir de 2012-2013. Ainda segundo este autor, esse ponto levou a uma gradual deserção da burguesia interna do governo ${ }^{25}$. Em um quadro de crise econômica como o que vimos, é de se supor que as políticas sociais do antigo governo passassem a atingir mais diretamente os interesses do conjunto da burguesia, sobretudo a política de valorização do salário mínimo, a de maior impacto no combate à desigualdade (PAULANI, 2017).

${ }^{25}$ Essa hipótese também é levantada por Singer (2016) e Braga (2016). Braga (2016) não trata dos conflitos interno da burguesia e Singer (2016) opõe uma coalizão produtivista, mais próxima ao governo, a outra de caráter rentista, identificada com o PSDB. 
Em um primeiro momento, o governo Temer tentou uma interlocução com os movimentos sociais e o sindicalismo. Em reportagem da Folha de S. Paulo reproduzida pelo site da Força Sindical, datada de 1/05/2016, o presidente da Força Sindical, Paulo Pereira da Silva, afirma ter recebido "carta branca" de Temer para ouvir as demandas dos movimentos sociais. Contudo, a retomada da agenda neoliberal com bastante celeridade (privatizações, reforma da previdência, reforma trabalhista, teto de gastos públicos) inviabilizou esse diálogo e enfrentou resistência dos sindicatos que convocaram manifestações e três greves gerais no período estudado (24 de maio, 28 de abril e 30 de junho de 2017). A primeira e a segunda tiveram maior adesão, sendo que a de abril protagonizou uma grande marcha em Brasília que terminou em uma brutal repressão. Segundo a CUT, 35 milhões de brasileiros teriam se mobilizado neste dia $^{26}$. A Federação do Comércio de São Paulo avaliou os prejuízos da greve geral de abril em cerca de 5 bilhões de reais ${ }^{27}$. Por sua vez, a convocatória para junho teve uma adesão menor, não contando, por exemplo, com o estratégico setor de transportes que havia aderido à greve no mês de abril. As centrais acabaram abandonando a própria qualificação de "greve geral" e passaram a falar em "paralisação"28. As razões pelas quais houve esse movimento nos parecem dignas de um estudo que pretendemos desenvolver futuramente.

Essa nova situação se diferenciava da disputa em torno do impeachment em que as centrais sindicais e os principais sindicatos do país não tiveram grande protagonismo nas manifestações de rua. Embora dessem apoio logístico, tudo indica que as suas bases não aderiram maciçamente às

${ }^{26}$ O Dia. Greve foi geral, mas não parou o país. 29/04/2017. Disponível em: < https:/ / odia.ig.com. br/brasil/2017-04-28/greve-foi-geral-mas-nao-parou-o-pais.html >. Acesso em: 28/03/2018. ${ }^{27}$ Jornal Estado de Minas. Greve geral provocou rombo de R\$ 5 bi no comércio brasileiro, diz. FecomercioSP. 29/04/2017.Disponívelem:<https://www.em.com.br/app/noticia/economia/2017/04/29/ internas_economia,866028/greve-provocou-rombo-de-r-5-bi-no-comercio-brasileiro-dizfecomercio.shtml >. Acesso em: 28/03/2018.

${ }^{28}$ Folha de S. Paulo. Força e UGT esperam mobilização menor para paralisação de sexta. Mercado, 29/06/2017. Disponível em: < http://www1.folha.uol.com.br/mercado/2017/06/1896912forca-e-ugt-esperam-mobilizacao-menor-para-paralisacao-de-sexta.shtml>. Acesso em: $28 / 03 / 2018$. 
manifestações (GALVÃO \&amp; MARCELINO, 2018). As razões para tanto não foram ainda suficientemente analisadas do ponto de vista acadêmico, contudo, pensamos que é possível afirmar que o sindicalismo tem sido um importante agente na crise política. Em relação ao impeachment, pode-se afirmar que as reformas neoliberais, têm muito menos mediações ideológicas e políticas, dizendo respeito diretamente a problemas muito concretos do cotidiano do trabalhador (emprego, condições de trabalho, salário, aposentadoria etc.).

Desse modo, as centrais sindicais obtiveram maior êxito em mobilizar as suas bases. Durante o governo Temer temos um período de unidade relativa entre as centrais, não necessariamente em torno de estratégias de luta, mas de bandeiras de luta. Essa unidade se dá em torno de pautas defensivas, caracterizando uma mudança do caráter do ciclo grevista (MARCELINO, 2017). O fato de as mobilizações contra as reformas do governo Temer não terem impedido a aprovação da Reforma Trabalhista, bem como o arquivamento da denúncia da PGR, que envolvia diretamente o então presidente em um caso de corrupção, parecem ser elementos que retiram o fôlego de mobilização dos trabalhadores. Isto é, embora tenham protagonizado grandes manifestações, parece haver um sentimento de que não foi o suficiente para mudar a agenda política do país. Poderíamos nos questionar se esse quadro abre um período de refluxo. Pensamos ser plausível levantar a hipótese de que o ciclo anterior (ofensivo e de algumas conquistas importantes para o sindicalismo) não se converteu em saldo organizativo, comprometendo a resistência a essa agenda. Além disso, os escândalos de corrupção envolvendo diretamente o poder central e a deterioração dos índices econômicos no país, sobretudo o desemprego e o poder de compra dos trabalhadores, frustraram a promessa de que os problemas do país seriam resolvidos com o impeachment da presidente Dilma Rousseff, discurso adotado pela oposição.

No governo Temer, a crise econômica se agravou e a crise política não cessou. Dados do IBGE demonstram que, entre 2016 e 2017, 2 milhões de pessoas ultrapassaram a linha de pobreza e 1,7 milhão passaram para a pobreza extrema (MUNDO SINDICAL, 06/12/2018). Como destaca Biancareli (2017), a campanha do impeachment foi construída também em 
torno de grandes promessas de recuperação da confiança do empresariado que passaria a investir, uma vez sem Dilma Rousseff, o Brasil teria um governo responsável do ponto de vista fiscal. Essa promessa não se cumpriu. Se entre 2015 e 2016 o Brasil viveu a sua segunda pior recessão da história, acumulando uma queda de 7\% no PIB, o crescimento de 1\% obtido em 2017 pode, de acordo com o DIEESE (14/05/2018) ser considerado pífio sobretudo devido ao modo como ocorreu: sustentado pelo "agronegócio, aliado à expansão da produção de automóveis e à sustentação do consumo, com a liberação do FGTS (Fundo de Garantia do Tempo de Serviço)". Ainda de acordo com o DIEESE (14/05/2018), em 2017 a indústria ainda estava paralisada e o desemprego era uma realidade para cerca de 13,7 milhões de brasileiros.

Do ponto de vista sindical, o patamar de greves continuou elevado, mas em clara situação desfavorável para os trabalhadores. Em 2016, foram registradas 2.093 greves, das quais 80\% (1.694) foram defensivas. Esse perfil foi semelhante ao de 2017 , que registrou uma queda no número de greves (1.556) das quais 81\% (1.269) foram defensivas (DIEESE, 2017, 2018).

Reconhecemos que as hipóteses levantadas neste artigo, para serem comprovadas, carecem de um conjunto de pesquisas a serem realizadas a partir dos desdobramentos do processo anteriormente descrito, envolvendo métodos quantitativos e qualitativos. Atualmente, em fase ainda inicial, estamos desenvolvendo uma pesquisa de mestrado que visa contribuir nesse sentido; isto é, a melhor compreensão desse tema candente auxilia a compreender a natureza do processo político contemporâneo a partir da dinâmica dos conflitos de classe.

\section{REFERÊNCIAS BIBLIOGRÁFICAS}

ALTHUSSER, Louis. Sobre o trabalho teórico. Lisboa, Editorial Presença, $\mathrm{s} / \mathrm{d}$.

ALVES, Giovanni. Trabalho e neodesenvolvimentismo. Choque de capitalismo e degradação do trabalho no Brasil. Bauru, Projeto Editorial Práxis, 2014. 
ANTUNES, Ricardo. O Continente do Labor. São Paulo, Boitempo, 2011.

ARAÚJO, Ângela \&amp; VÉRAS DE OLIVEIRA, Roberto. El sindicalismo brasileño en la Era de Lula. Revista Latinoamericana de Estudios del Trabajo, vol. 5, pp. 83-112, 2011.

BASTOS, Pedro Paulo Zahluth. Que horas ela volta? Economia política e política econômica de Lula a Dilma. In MARINGONI, Gilberto \&amp; MEDEIROS, Juliano (orgs.). Os cinco mil dias do lulismo. São Paulo, Boitempo/Fundação Lauro Campos, 2017, pp. 77-90.

BOITO JR. Os atores e o enredo da crise política. In JINKINGS, Ivana et alli. Por que gritamos golpe? São Paulo, Boitempo Editorial, 2016, pp. 23-30.

BOITO JR. Estado, politica e classes sociais. São Paulo, UNESP, 2007.

BOITO JR. O sindicalismo de Estado no Brasil. São Paulo, HUCITEC, 1991.

BOITO JR. A nova fase do capitalismo neoliberal no Brasil e sua inserção no quadro político da América Latina. In ALIAGA, Luciana et al. Marxismo. Teoria, História e Política. São Paulo, Alameda, 2011, pp. 125-140.

BOITO JR. \&amp; MARCELINO, Paula. O sindicalismo deixou a crise para trás? Um novo ciclo de greves na década de 2000. Cad. CRH [online]. 2010, vol.23, n.59, pp. 323-338.

BOITO JR.; et al. A nova fase do sindicalismo brasileiro. In CESIT; UGT (orgs.). Sindicalismo contemporâneo. Uma nova visão para o movimento sindical brasileiro, São Paulo, 2015, pp. 206-223.

BOITO JR., Armando \&amp; SAAD-FILHO, Alfredo. State, State institutions and Political Power in Brazil. Latin American Perspectives, Vol.43, n.2, pp. 190-206.

BRAGA, Ruy. A politica do precariado. Do populismo à hegemonia lulista. São Paulo, Boitempo Editorial, 2012. 
BRAGA, Ruy. Terra em transe: o fim do lulismo e o retorno da luta de classes in SINGER, André \&amp; LOUREIRO, Isabel (orgs.). As contradições do lulismo. São Paulo, Boitempo Editorial, 2016, pp. 55-92.

BRESSER-PEREIRA, L. C. Do antigo ao novo desenvolvimentismo na América Latina. Texto para discussão, São Paulo, n. 275, nov. 2010. Disponível em: <http://www.bresserpereira.org.br/ papers/2012/12.Do_antigo_ao_novo_desenvolvimentismo.pdf $>$. Acesso em: 27/04/2016.

BRESSER-PEREIRA, L. C. A construção politica do Brasil. Sociedade, economia e Estado desde a Independência. São Paulo, Editora 34, [3ª edição], 2016 a.

BRESSER-PEREIRA, L. C. Reflexões sobre o Novo Desenvolvimentismo e o Desenvolvimentismo Clássico. Revista de Economia Política, vol. 36, n.2 (143), pp. 237-265, abril-junho, 2016b.

BIANCARELI, André. O governo Temer na economia: conjuntura, estrutura e "fracasso". Le Monde Diplomatique, agosto, 2017. Disponível em: < https://diplomatique.org.br/o-governo-temer-na-economiaconjuntura-estrutura-e-fracasso/ > . Acesso: 08/06/2019.

CARDOSO, Adalberto. Sindicato no Brasil: passado, presente e futuro. In: CAT'TANI, Antonio David (Org.). Trabalho: horizonte 2021, pp. 121146. Porto Alegre: Escritos Editora, 2014.

CARDOSO, Adalberto. Dimensões da crise do sindicalismo. Caderno CRH [On-line]. 2015, vol. 28, n.75, pp. 493-510. Disponível em: < http:// www.scielo.br/pdf/ccrh/v28n75/0103-4979-ccrh-28-75-0493.pdf>. Acesso em: 30/07/2018.

CARVALHO, Francisco Prandi Mendes de. O sindicalismo brasileiro nos governos do PT: um balanço crítico da bibliografia. Relatório de Iniciação científica, FAPESP, mimeo, 2016.

CAVALCANTE. Sávio. Classe média e conservadorismo liberal. In VELASCO E CRUZ, Sebastião et al. Direita volver! O retorno da direita e o ciclo político brasileiro. São Paulo, Fundação Perseu Abramo, pp. 177196. 
DOBRY, Michel. Sociologia das crises políticas: a dinâmica das mobilizacoões multissetoriais. São Paulo, Ed. Unesp, 2014.

DRUCK, Graça. Os sindicatos, os movimentos sociais e o governo Lula: cooptação e resistência. In OSAL, ano VI, n¹9. CLACSO, Buenos Aires, Argentina, Julio 2006.

FERRAZ, Marcos \&amp; BRIDI, Maria Aparecida. Olhares sindicais sobre o governo Lula: a percepção dos dirigentes sindicais. In OLIVEIRA, Roberto Véras et al. O sindicalismo na era Lula: paradoxos, perspectivas, olhares. Belo Horizonte, Fino Traço, 2014, pp. 87-114.

FILGUEIRAS, Luis. O neoliberalismo no Brasil: estrutura, dinâmica e ajuste do modelo econômico in BASUALDO, Eduardo M.\&amp; ARCEO, Enrique (Comp.) Neoliberalismo y sectores dominantes. Tendencias globalesy experiencias nacionales. Buenos Aires, Consejo Latinoamericano de Ciencias Sociales (CLACSO), 2006.

GALVÃO, Andréia. A reconfiguração do movimento sindical no governo Lula. In: BOITO JR., Armando \&amp; GALVÃO, Andréia (orgs.). Política e classes sociais no Brasil dos anos 2000. São Paulo: Alameda, 2012, pp. 187-221.

GALVÃO, Andréia.; \&amp; MARCELINO, Paula. O sindicalismo brasileiro diante do golpe. In: Sayonara Grillo Coutinho et al. (Org.). Reformas institucionais de austeridade, democracia e relações de trabalbo. São Paulo, LTr, 2018, v. 1, p. 85-96.

GRAMSCI, Antonio. Maquiavel, a Política e o Estado moderno. Rio de Janeiro, Civilização Brasileira, 1978.

[JURUNA] João Carlos Gonçalves. Os trabalhadores e o dia seguinte. Portal O Vermelho. Disponível em: < http://www.vermelho.org.br/ noticia/279495-1 >. 18/04/2016. Acesso em: 01/03/2018.

KATZ, Cláudio. Neoliberalismo, Neodesenvolvimentismo, Socialismo. São Paulo, Expressão Popular/Fundação Perseu Abramo, 2016. 
KOWARICK, Lúcio. Capitalismo e marginalidade na América Latina. Rio de Janeiro, Paz e Terra, 1977.

LADOSKY, Mario Henrique Guedes; et al. A questão trabalhista e os desafios da ação sindical nos anos 2000. In OLIVEIRA, Roberto Véras; et al. O sindicalismo na era Lula: paradoxos, perspectivas, olhares. Belo Horizonte, Fino Traço, 2014, pp. 61-85.

LADOSKY, Mário Henrique Guedes; RODRIGUES, Iram Jácome. A CUT e o sindicalismo brasileiro nos anos recentes. Limites e possibilidades. Tempo Social, ver. De sociologia da USP, v.30, n1, pp. 53-76.

MACHADO, João. O que foi o Programa Democrático e Popular do PT? Mimeo. Disponível em:<http://www.consultapopular.org.br/sites/default/ files $/ \mathrm{O} \% 20$ que $\% 20$ foi $\% 20$ o\%20PDP.pdf> Acesso em 31/05/2018.

MARCELINO, Paula. Sindicalismo e neodesenvolvimentismo. Analisando as greves entre 2003 e 2013 no Brasil. Tempo Social, revista de sociologia da USP, v.29, n.3, pp. 201-227.

MARTUSCELLI, Danilo. Crises politicas e capitalismo neoliberal no Brasil. Curitiba, Editora CRV, 2015.

MATTTOS, Marcelo Badaró. Trabalhadores e sindicatos no Brasil. São Paulo, Expressão Popular, 2009.

MORAIS, Lécio. A perda de competitividade externa e a ruptura da aliança de classe no governo Dilma Rousseff. In RABELO, Renato \&amp; MONTEIRO, Adalberto. Governos Lula e Dilma: O ciclo golpeado. São Paulo, Fundação Maurício Grabois/Ed. Anita Garibaldi, 2017, pp. 177-208.

NETO, Antonio. Carta de desfiliação. Disponível em:<https://jornalggn. com.br/sites/default/ files / documentos / pmdboficio.pdf $>$ 03/07/2017. Acesso em: 05/03/2018.

OLIVEIRA; Francisco. O ornitorrinco. In: Crítica à razão dualista/O ornitorrinco. São Paulo; Boitempo; 2003, pp. 121-150. 
PAULANI, Leda. Desenvolvimentismo, planejamento e investimento público. In MARINGONI, Gilberto \&amp; MEDEIROS, Juliano (orgs.). Os cinco mil dias do lulismo. São Paulo, Boitempo/Fundação Lauro Campos, 2017, pp. 91-100.

POULANTZAS, Nicos. As classes sociais no capitalismo de hoje. Rio de Janeiro, Zahar, 1975.

POUlANTZAS, Nicos. Poder político e classes sociais. São Paulo, Martins Fontes, 1977a.

POULANTZAS, Nicos. A crise das ditaduras. São Paulo, Paz e Terra, 1978.

POULANTZAS, Nicos. As transformações atuais do Estado, a crise política e a crise do Estado in _.. (org.). O Estado em crise, Rio de Janeiro, Graal, 1977b, pp. 3-41.

SAES, Décio. A política neoliberal e o campo político conservador no Brasil atual in _... República do Capital. Boitempo Editorial, 2001, pp. 81-92.

POULANTZAS, Nicos. Estado e Democracia: ensaios teóricos. Unicamp, IFCH, 1998.

SAMPAIO JR., Plínio de Arruda. Desenvolvimentismo e neodesenvolvimentismo: tragédia e farsa. IE-UNICAMP, 2012.

SINGER, André. A (falta de) base política para o ensaio desenvolvimentista. In __.\&amp; LOUREIRO, Isabel (orgs.). As contradições do lulismo. São Paulo, Boitempo Editorial, 2016, pp. 21-54.

SINGER, André. Os sentidos do lulismo. São Paulo, Cia. Das Letras, 2012.

SINGER, André. O lulismo em crise. São Paulo, Cia. Das Letras, 2018.

SOARES, José de Lima; As centrais sindicais e o fenômeno do transformismo no governo Lula in Revista Sociedade e Estado. Vol. 28; n.3. Setembro-Dezembro; 2013.

SÓRIA e SILVA, S. Interseção de classes: fundos de pensão e sindicalismo no Brasil. Tese de doutorado em Sociologia, Unicamp, Campinas, 2011. 
TATAGIBA, Luciana; et al. Protestos à direita no Brasil (2007 - 2015). In VELASCO E CRUZ, Sebastião; et al. Direita volver! O retorno da direita e o ciclo político brasileiro. São Paulo, Fundação Perseu Abramo, pp. 197-212.

TROTSKY, Leon. Os sindicatos na época da transição. In AGUENA, Pablo (org). O marxismo e os sindicatos. Marx, Engels, Lenin e Trotsky. São Paulo, Sundermann, 2008, pp. 195-198.

\section{FONTES}

CONFEDERAÇÃO NACIONAL DA INDÚSTRIA. A indústria em números, dezembro 2016. Disponível em: http://arquivos. portaldaindustria.com.br/app/cni_estatistica_2/2015/02/11/165/ Industria_Numeros_dezembro2016.pdf?r $=0.530258823916$. Acesso em: 28/03/2018).

DIEESE. Boletim de conjuntura. 14/05/2018. Disponível em: < https://www. dieese.org.br/boletimdeconjuntura/2018/boletimConjuntura014. pdf $>$. Acesso em: 08/06/2019.

FORÇA SINDICAL. Lula recebe dirigentes da Força para discutir saídas políticas e econômicas. Disponível em: < http://www.fsindical.org. $\mathrm{br} /$ imprensa/lula-recebe-dirigentes-da-forca-para-discutir-saidaspoliticas-e-economicas $>$. Acesso em: 07/02/2019.

FORÇA SINDICAL. Paulinho da Força faz ponte de Temer com grupos próximos do PT. 01/05/2016. Disponível em: < http://www. fsindical.org.br/imprensa/paulinho-da-forca-faz-ponte-de-temercom-grupos-proximos-ao-pt > . Acesso em: 23/05/2019.

MINISTÉRIO DO TRABALHO. Divulgada relação das centrais sindicais certificadas para 2016. 01/04/2016. Disponível em: < http:// trabalho.gov.br/noticias/3202-divulgada-relacao-das-centraissindicais-certificadas-para-2016 >. Acesso em: 07/12/2016. 
MUNDO SINDICAL. Com Temer, pobreza cresce e atinge mais de 54 milhões de pessoas, diz IBGE. 06/12/2018. Disponível em: <http:/ /www.mundosindical.com.br/Noticias/34873,Com-Temerpobreza-cresce-e-atinge-mais-de-54-milhoes-de-pessoas-diz-IBGE>. Acesso em 08/06/2019.

Texto recebido em 12/02/2019 e aprovado em 19/06/2019 
